\title{
SATISFAÇÃO DE PUÉRPERAS APÓS INTERVENÇÃO FISIOTERAPÊUTICA EM EDUCAÇÃO EM SAÚDE
}

\section{Jordana Barbosa da Silva}

Mestranda do Laboratório de Pesquisa em Saúde da Mulher, Departamento de Fisioterapia da Universidade Federal de São Carlos (UFSCar), Brasil.

\section{Gabrielle Esther Doi}

Discente de Fisioterapia, Departamento de Reabilitação e Prevenção em Fisioterapia da Universidade Federal do Paraná (UFPR), Brasil.

\section{Laysse Candido da Silva}

Discente de Fisioterapia, Departamento de Reabilitação e Prevenção em Fisioterapia da Universidade Federal do Paraná (UFPR), Brasil.

\section{Maria Izabel Feltrin}

Discente de Fisioterapia, Departamento de Reabilitação e Prevenção em Fisioterapia da Universidade Federal do Paraná (UFPR), Brasil.

\section{Talita Gianello Gnoato Zotz}

Docente Doutora em Fisioterapia, Departamento de Reabilitação e Prevenção em Fisioterapia da Universidade Federal do Paraná (UFPR), Brasil.

\section{Raciele Ivandra Guarda Korelo}

Docente Doutora em Fisioterapia, Departamento de Reabilitação e Prevenção em Fisioterapia da Universidade Federal do Paraná (UFPR), Brasil.

\section{Rubneide Barreto Silva Gallo}

Docente Doutora em Fisioterapia, Departamento de Reabilitação e Prevenção em Fisioterapia da Universidade Federal do Paraná (UFPR), Brasil.
RESUMO: O objetivo deste estudo foi avaliar a satisfação de puérperas após intervenção fisioterapêutica em educação em saúde. Estudo transversal e observacional que contou com a participação de 63 puérperas internadas em alojamento conjunto de uma maternidade. Foram realizadas atividades de educação em saúde abordando modificações e adaptações do puerpério, utilizando materiais de apoio de baixo custo, linguagem simples e exercícios preventivos. As mulheres também receberam uma cartilha educativa elaborada pelos pesquisadores. Posteriormente, foi realizada a avaliação da satisfação da puérpera em relação ao atendimento fisioterapêutico. A maioria das puérperas apresentou-se muito satisfeitas $(55,5 \%)$ e satisfeitas $(44,4 \%)$ com o atendimento. O esclarecimento de dúvidas foi melhor que esperado (39,6\%) e como esperado (47,6\%). A maioria das participantes sanou dúvidas (93,6\%), afirmou que participaria novamente da atividade e recomendaria a assistência para outras mulheres (93,6\%). Estratégias fisioterapêuticas de educação em saúde são satisfatórias para mulheres do puerpério imediato.

PALAVRAS-CHAVE: Educação em Saúde; Fisioterapia; Maternidade; Puerpério.

\section{SATISFACTION OF PUERPERAL FEMALES AFTER PHY- SIOTHERAPY INTERVENTION IN HEALTH EDUCATION}

ABSTRACT: The satisfaction of puerperal females after physiotherapy intervention in health education is evaluated. Current transversal and observational study involved 63 puerperal females hospitalized in the maternity ward. Health education activities were undertaken dealing with puerperal modifications and adaptations, employing low cost material, simple diction and preventive exercises. They also received an educational handout prepared by the researchers. Puerperal satisfaction was then evaluated with regard to physiotherapy care. Most puerperal females were very satisfied (55.5\%) and satisfied (44.4\%) with the care. Quitting doubts was more than expected (39.6\%) and as expected (47.6\%). Most participants said they did not have any more doubts (93.6\%) and would participate in the activity once more and would recommend it to other women (93.6\%). Physiotherapy strategies in health education are satisfactory for immediate puerperal females.

KEY WORDS: Health education; Physiotherapy; Maternity; Puerperium. 


\section{INTRODUÇão}

O Ministério da Saúde define as estratégias de educação em saúde como "um conjunto de saberes teóricos e práticos que visa a construção e compreensão de aspectos relacionados a saúde, com intuito de aumentar a autonomia da população sobre seu próprio cuidado"1. Desta forma, o paciente adquire conhecimentos sobre seu bem-estar e torna-se o principal responsável por sua saúde, o que pode levar o indivíduo a aumentar a qualidade de vida por meio da mudança de hábitos ${ }^{2,3}$.

Frente às transformações biológicas, psicológicas, comportamentais e socioculturais das mulheres no puerpério imediato (período compreendido desde o primeiro ao décimo dia após o parto) $)^{4,5,6}$, a continuidade de prestação de cuidados relacionados à saúde da mulher é essencial ${ }^{7}$, uma vez que nesta fase que as puérperas estão sensibilizadas a receberem influências dos profissionais da saúde e as ações de promoção à saúde podem ser bem recebidas ${ }^{8}$.

As abordagens utilizadas em atividades de educação em saúde nesta fase permitem que as mulheres possam conhecer melhor o próprio corpo e entendam as mudanças físicas e emocionais que ocorrem durante $o$ pós-parto. Desta forma, os profissionais da saúde têm a missão de atenderem a puérpera de forma integral, levando em conta o contexto sociocultural e familiar ${ }^{4}$, mantendo a individualidade e características singulares de cada mãe $e^{9}$. Além disso, a troca de experiências e aprendizado entre profissional da saúde e paciente é importante para que se possa entender e solucionar as necessidades das mulheres $^{10}$.

O fisioterapeuta é considerado um profissional que possui formação acadêmica para atuar frente aos programas de educação em saúde. Seguindo as Diretrizes Curriculares Nacionais (DCNs) para os cursos superiores, direcionadas também ao curso de Fisioterapia, a formação do acadêmico deve ser generalista, humanista, crítica e reflexiva, o que auxilia o profissional a desenvolver capacidades que o permitam realizar ações de atenção à saúde em diferentes níveis de complexidade (promoção, prevenção, recuperação e reabilitação), tanto de maneira individual quanto coletiva ${ }^{11}$. A participação do discente em programas de extensão é complementar à formação teórica do fisioterapeuta e proporciona um processo de aprimoramento da graduação e da capacitação profissional devido à atuação do acadêmico em cenários reais. Além disso, as atividades desenvolvidas pelas extensões universitárias funcionam como uma forma de exercício da responsabilidade social das instituições superiores ${ }^{12}$.

Embora a literatura já tenha sugerido que o fisioterapeuta pode auxiliar na melhoria da saúde da mulher por meio de programas de promoção em saúde ${ }^{13}$, o mais recorrente é encontrar estes profissionais frente à recuperação e reabilitação de seus pacientes, portanto, em níveis secundários e terciários de atenção $0^{14}$. Mais escasso ainda é encontrar o fisioterapeuta inserido em equipes multiprofissionais em maternidades.

Embora a assistência fisioterapêutica na obstetrícia e ginecologia seja vista como essencial para melhorar a prestação de serviços maternos ${ }^{15}$, a maioria dos estudos realizados sobre os cuidados da mulher no puerpério descrevem a atuação de enfermeiros. Além disso, no cenário atual, observa-se que a maioria dos cuidados e ações educativas no puerpério são direcionados ao cuidado do recém-nascido, e não à puérpera ${ }^{16}$. No estudo de Dodou et al. ${ }^{17}$, as puérperas relataram terem recebido apenas orientações direcionadas à atenção do recém-nascido e enfatizaram que não receberam informações a respeito do próprio cuidado, reforçando que o foco das atividades no pós-parto está voltado para estratégias de atenção ao bebê. Resultados semelhantes foram encontrados na pesquisa de Corrêa et al. ${ }^{18}$ e na metassíntese de Correa et al. ${ }^{19}$, na qual as puérperas relataram incômodo e frustração devido atenção focalizada apenas no bebê.

Partindo-se desse pressuposto, estudos que abordem a atuação do fisioterapeuta em programas de promoção em saúde com enfoque na puérpera são relevantes. Sendo assim, o objetivo deste estudo foi avaliar a satisfação de puérperas após intervenção fisioterapêutica em educação em saúde.

\section{METODOLOGIA}

Trata-se de um estudo transversal e observacional realizado por acadêmicas de um projeto de extensão e de iniciação científica do curso de Fisioterapia de uma 
Instituição de Ensino Superior, aprovado pelo Comitê de Ética $n^{0}$ 1.674.698; CAA 56163616.8.0000.0096. As mulheres que aceitaram participar da atividade receberam o Termo de Consentimento Livre e Esclarecido (TCLE) para que, então, a atividade em educação em saúde tivesse início.

Este estudo contou com a participação de 63 puérperas de baixo risco internadas no alojamento conjunto de uma maternidade que não contava com a atuação de um fisioterapeuta contratado para o cuidado e a atenção às puérperas. As atividades ocorreram às sextas-feiras à tarde, entre fevereiro a junho de 2017, totalizando 22 encontros entre acadêmicas do curso de Fisioterapia e puérperas.

Durante as atividades realizadas na maternidade, os acadêmicos eram acompanhados pela docente responsável pelo projeto. Todas as atividades foram voltadas para a fase do puerpério imediato, de 8 a 48 horas após o parto, em que todas as puérperas internadas recebiam orientações por meio da educação em saúde.

A intervenção ocorreu em um único momento durante a visitação aos quartos das puérperas. A maternidade em questão possui 14 quartos, os quais comportavam no máximo 4 leitos, 4 berços do recém-nascido e 4 poltronas do acompanhante. Em cada quarto visitado, as puérperas e seus acompanhantes eram convidados a participar das atividades e as acadêmicas de Fisioterapia realizavam uma breve explicação sobre a atuação fisioterapêutica no puerpério e os benefícios e relevância da educação em saúde.

Inicialmente foram realizadas palestras de educação em saúde, abordando modificações físicas e adaptações do puerpério, com utilização de materiais de apoio de baixo custo, instruções verbais de linguagem simples e exercícios preventivos; em seguida, entrega de uma cartilha educativa formulada com base nas temáticas do encontro; e, posteriormente, a avaliação da satisfação da puérpera em relação ao atendimento fisioterapêutico em educação em saúde recebido por meio de preenchimento de um questionário. A cartilha educativa foi desenvolvida pelos próprios pesquisadores.

Os temas abordados nas intervenções contemplavam as alterações respiratórias e posturais da mulher, posicionamentos ergonômicos para realização das atividades de vida diária (AVD), conscientização e incentivo a contração da musculatura do assoalho pélvico (MAP), origem e localização da diástase do músculo reto abdominal, aspectos da depressão pós-parto, os cuidados com a mama e a amamentação. Todas as informações transmitidas para as puérperas foram de fácil compreensão e de linguagem simples.

Para auxiliar as atividades e facilitar a compreensão das informações, foram utilizados diferentes materiais de apoio, como:

a) Boneco de pano, que representava o bebê recém-nascido, e era utilizado para simular diversos posicionamentos da mãe e do bebê durante execução de AVD e amamentação. O boneco apresentava uma abertura semelhante à boca do recém-nascido, e esta característica do material auxiliava na demonstração do posicionamento de pega e sucção do bebê na mama durante a amamentação (Figura 1a);

b) Molde de mamas feito de crochê, que ilustrava os diferentes tipos de mamilo, utilizado para exemplificar os cuidados com a mama (Figura 1b);-

c) Próteses de gesso do sistema reprodutor feminino (contemplando estruturas internas e externas) e cartilhas ilustrativas da MAP, materiais utilizados para auxiliar no aumento da percepção e conscientização da MAP (Figura 1c e 1d);

d) Cartazes informativos com figuras ilustrativas sobre a diástase do músculo reto abdominal, utilizados para demonstrar a origem e localização desta alteração musculoesquelética;

e) Placas de papel com os dizeres "verdadeiro" e "falso", as quais eram distribuídas às puérperas, para que as mesmas respondessem questões formuladas pelos discentes. Esta ferramenta foi utilizada com intuito de tornar as intervenções dinâmicas e participativas. Os temas relacionados a este material envolviam a depressão pós-parto e as alterações físicas durante o puerpério. Após a resposta ao questionamento, as discentes realizavam uma breve explicação sobre o tema. Esta conversa ocorria de maneira informal, a fim de transmitir segurança para as puérperas e esclarecer dúvidas. 

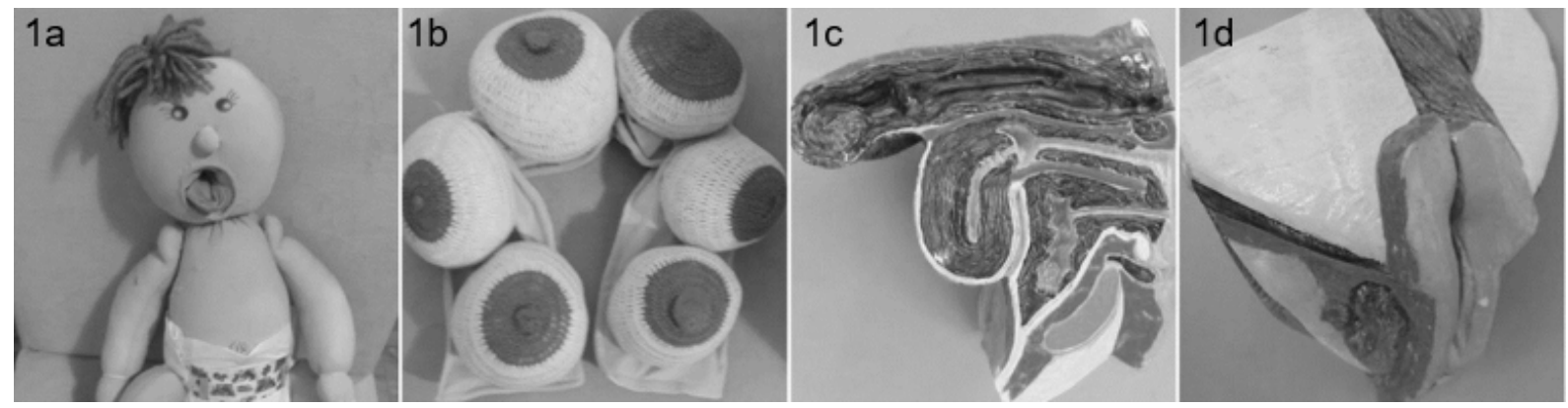

Figura 1. Materiais de apoio utilizados nas intervenções fisioterapêuticas de educação em saúde na maternidade.

Fonte: Os autores (2018).

Após a explanação dinâmica de cada tema, as puérperas eram solicitadas pelo grupo a reconhecerem partes de seu corpo como, por exemplo, localizar o próprio diafragma, perceber a diástase de reto abdominal e reconhecer seu assoalho pélvico. Além disso, eram instigadas a realizarem exercícios para prevenção de disfunções puerperais.

Ao final da atividade, as puérperas recebiam uma cartilha educativa, elaborada pelo grupo de acadêmicas do projeto e docentes responsáveis, intitulada de "Cuide-se no pós-parto: a Fisioterapia ajuda você". O conteúdo deste material visava a ressaltar as orientações fisioterapêuticas realizadas nas atividades presenciais nos alojamentos e estimular a realização das mesmas em domicílio. A cartilha era composta por temas já explanados, como exercícios respiratórios, exercícios para a diminuição da diástase abdominal, exercícios de fortalecimento da MAP, alongamentos de membros inferiores e tronco, posturas ergonômicas para realização de AVD e no cuidado com o bebê, massagem estimulante para mamilos e seios e a importância da amamentação.

Além disso, as puérperas receberam um questionário para mensurar a satisfação com o atendimento fisioterapêutico. O instrumento utilizado foi idealizado e adaptado com base no American Customer Satisfaction Index (ACSI), proposto por Fornell et al. ${ }^{20} \mathrm{O}$ modelo do ACSI apresenta medidas válidas e avalia de forma mais apropriada a satisfação de indivíduos quando comparado ao modelo europeu (Lopes et al., 2009). Com base na estrutura do ACSI (qualidade percebida, expectativas, valor percebido, satisfação, lealdade, reclamação), foram formuladas dez questões objetivas para avaliação do atendimento fisioterapêutico. A última questão do instrumento era um espaço para anotações discursivas, na qual as mulheres poderiam escrever opiniões e sugestões refe- rentes ao atendimento (Tabela 1). As puérperas deveriam assinalar uma única afirmativa para responder à questão. Para facilitar a escolha das respostas, cada afirmação possuía uma expressão gráfica respectiva (Figura 2): 1 - muita insatisfação/discordo totalmente; 2 - insatisfeito/discordo; 3 - indiferente/nem discordo nem concordo; 4 - satisfeito/ concordo; 5 - muito satisfeito/muito perto do ideal. Todas as questões possuíam a alternativa de resposta "não se aplica ou não sabe avaliar".

Os dados obtidos foram tabulados no Microsoft Excel 2010 e analisados por meio do software Statistical Package for the Social Sciences (SPSS). Optou-se por apresentar as variáveis nominais por meio da descrição da frequência (n) e porcentagem (\%). A partir da análise dos dados, foram elaborados gráficos de colunas para melhor observação dos dados.

Quadro 1. Perguntas do questionário de satisfação referente à conduta fisioterapêutica, adaptado de Fornell et al. ${ }^{20}$

\begin{tabular}{|l|}
\hline $\begin{array}{l}\text { Questionário de satisfação referente à conduta fisioterapêuti- } \\
\text { ca (adaptado de Fornell } \text { et al. } 1996)\end{array}$ \\
\hline 1. No geral, eu me senti satisfeita com a conduta fisioterapêutica. \\
\hline 2. Eu gostei muito da Fisioterapia. \\
\hline 3. Eu me senti frustrada com a Fisioterapia. \\
\hline 4. Eu me senti com raiva com a Fisioterapia. \\
\hline 5. A conduta realizada foi ideal para mim. \\
\hline 6. O atendimento realizado atendeu minhas expectativas/queixas. \\
\hline 7. Eu faria novamente o atendimento. \\
\hline 8. Eu recomendaria o atendimento para outras pessoas. \\
\hline $\begin{array}{l}\text { 9. Como foi a cordialidade e confiança proporcionada pelo fisio- } \\
\text { terapeuta? }\end{array}$ \\
\hline $\begin{array}{l}\text { 10. No geral, minhas dúvidas foram sanadas de modo claro du- } \\
\text { rante o atendimento. }\end{array}$ \\
\hline $\begin{array}{l}\text { 11. Descreva sua opinião ou sugestão para o atendimento fisiote- } \\
\text { rapêutico. }\end{array}$
\end{tabular}

Fonte: Os autores (2018). 


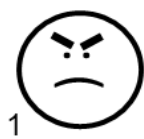

( ) Discordo totalmente

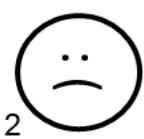

( ) Discordo

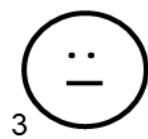

( ) Nem discordo, nem concordo

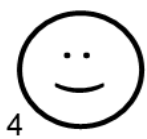

( ) Concordo

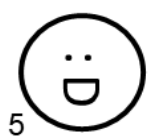

( ) Concordo totalmente

( )

Figura 2. Expressões gráficas ("emojis") que compunham o questionário de satisfação. Cada figura era acompanhada de uma frase teórica correspondente à numeração das ilustrações.

\section{RESULTADO}

Todas as puérperas disseram estarem satisfeitas ( $\mathrm{n}=28,44,4 \%)$ ou muito satisfeitas $(\mathrm{n}=35,55,5 \%)$ com a educação em saúde apresentada pelas acadêmicas de fisioterapia. Cerca de $60,3 \%(n=38)$ das participantes responderam que as condutas/orientações apresentadas foram ideais para as necessidades individuais e $34,9 \%$ (n $=22$ ) afirmaram que as condutas estavam próximas do ideal. Quanto às expectativas atendidas e queixas sanadas no decorrer da atividade, 39,6\% $(n=25)$ participantes afirmaram que as atividades foram muito melhores que 0 esperado e $47,6 \%(n=30)$ pontuaram que as atividades foram melhores do que esperado.
As mulheres afirmaram que participariam novamente do atendimento $(\mathrm{n}=59,93,6 \%)$ e que recomendariam a fisioterapia para outras mulheres $(\mathrm{n}=59$, 93,6\%). Apenas uma mulher relatou não estar satisfeita com a conduta realizada pela equipe, mas não justificou sua resposta. A maioria das participantes afirmou que a confiança proporcionada pelo fisioterapeuta foi muito melhor que o esperado $(n=31 ; 49,2 \%)$ e melhor que o esperado $(\mathrm{n}=25 ; 39,6 \%)$, apenas duas puérperas $(3,1 \%)$ selecionaram o item "nem melhor, nem pior". Todas as puérperas registraram que as dúvidas foram esclarecidas após a explanação da fisioterapia nas enfermarias ( $\mathrm{n}=$ 59, 93,6\%). Os resultados estão apresentados na Figura 3.

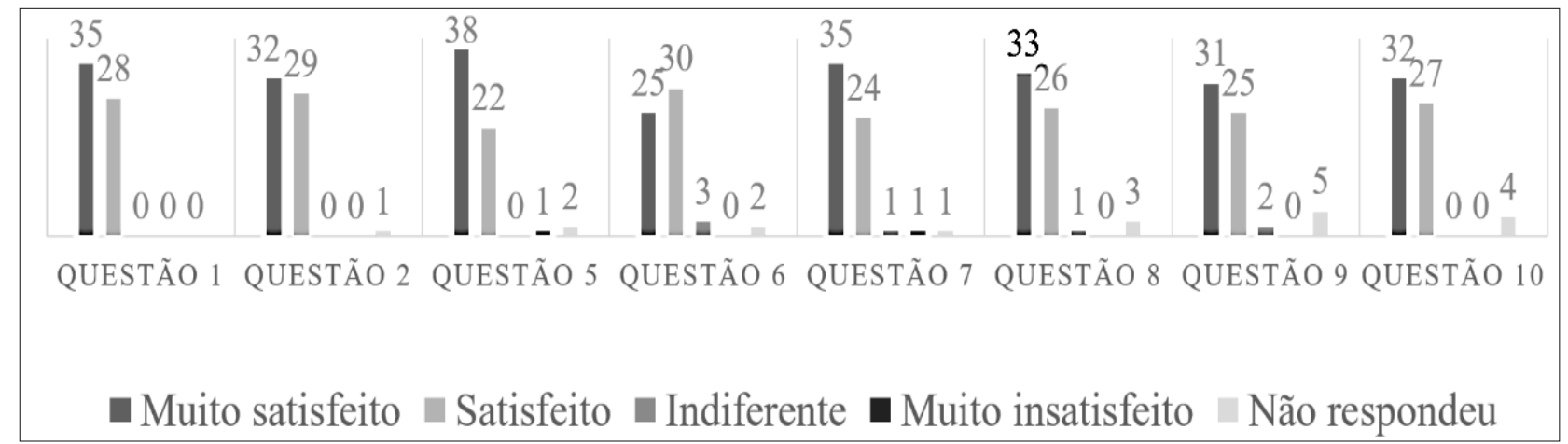

Figura 3. Avaliação da satisfação de puérperas quanto ao atendimento fisioterapêutico no pós-parto, por meio de questionário de satisfação adaptado ${ }^{20}$.

Duas perguntas do questionário de satisfação avaliaram frustrações ou raiva com o atendimento fisioterapêutico, neste caso a educação em saúde. Somente algumas mulheres relatam tais sentimentos, apresentados pelas questões 3 e $4(n=18,28,5 \%$; $n=9,14.2 \%$; respectivamente) mas não justificaram as respostas. $\mathrm{O}$ resultado está apresentado na Figura 4. 


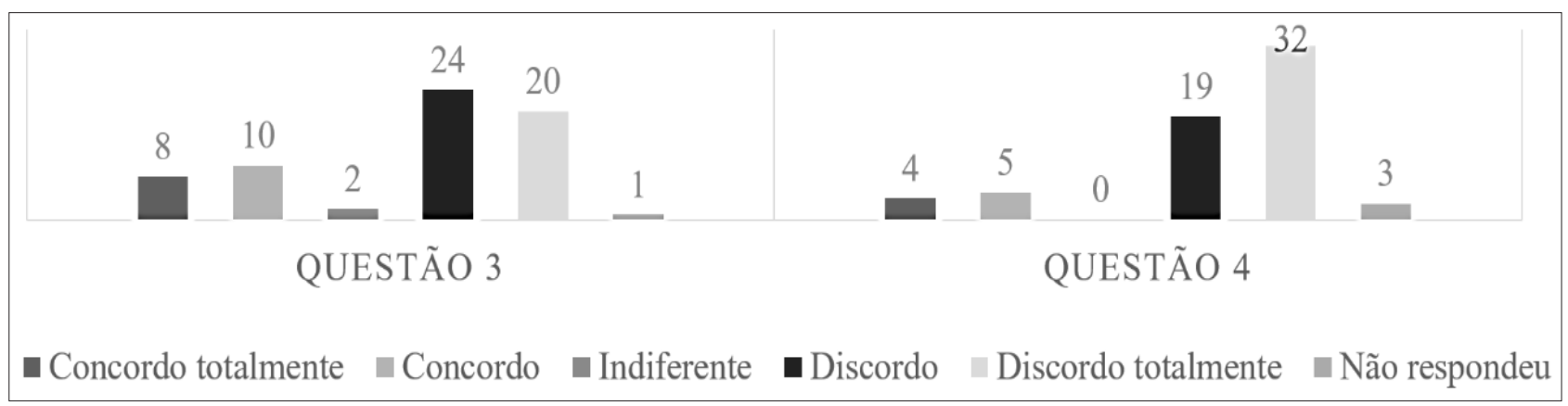

Figura 4. Avaliação quanto à frustação relacionada ao atendimento fisioterapêutico no pós-parto, por meio de questionário de satisfação adaptado ${ }^{20}$.

As puérperas elaboraram comentários positivos em relação ao atendimento fisioterapêutico na última questão do questionário utilizado. Não foram encontrados registros de comentários sobre decepção ou insatisfação com a conduta realizada. A seguir, estão apresentados alguns relatos das puérperas que participaram do estudo. E para manter a confidencialidade das participantes, as puérperas foram identificadas pela letra "P". Dentre as opiniões, as de destaque são:

Na minha opinião, foi muito bom, foram bem simpáticos, explicam tudo muito bem e com certeza eu participaria de novo. Parabéns. (P1)

Muito bom, deveria ter em todas as maternidades para o conhecimento de várias gestantes, pois eu mesma não sabia dessas orientações que vão melhorar a vida das mulheres após o parto. (P2)

Atendimento realizado com bastante cordialidade, dinamismo e atenção. Sanou e ajudou muitas dúvidas referentes à amamentação. Minha sugestão: não pare e se possível que possa se expandir, pois algumas orientações recebi somente no pós-parto. (P3)

Gostei muito do atendimento, as profissionais me deixaram à vontade, fiz perguntas e fui respondida com cordialidade. (P4)

Muito criativo e educativo, aprendi coisas que não sabia e vou desenvolver, vai ajudar muitas mães. (P5)

As fisioterapeutas passam confian- ça e entendimento do assunto. Eu gostei, as alunas explicaram todas as dúvidas que eu tinha. Excelente $\mathrm{e}$ divertido. (P6)

Por meio da análise observacional, os autores do presente artigo identificaram certo receio por parte das puérperas em participar das atividades logo no início da ação fisioterapêutica. Entretanto, no decorrer do encontro, a colaboração das mulheres aumentava. Uma das razões para o aumento da participação foi o incentivo de parceiros e familiares que estavam presentes no alojamento no momento da atividade. Estes participavam das dinâmicas e incentivavam as puérperas a fazerem o mesmo.

Notoriamente, as puérperas demonstraram uma maior atenção e interesse à explanação de temas como amamentação, alterações físicas no pós-parto e conscientização e fortalecimento da MAP. Ao passo que as acadêmicas utilizavam o molde dos diferentes tipos de mamilo e o boneco de pano na atividade sobre a amamentação, notava-se que as mulheres ficavam mais compenetradas nas orientações. O mesmo ocorria quando era abordado o tema sobre mudanças físicas no pós-parto e o fortalecimento da MAP.

No decorrer das atividades, as mulheres multíparas realizavam comentários e relatos quanto às experiências de suas gestações anteriores. As falas contemplavam as alterações musculoesqueléticas mais desconfortáveis durante o puerpério anterior e experiências anteriores com técnicas de fortalecimento da MAP. Além disso, muitas puérperas relataram, informalmente, dificuldade na amamentação. 
Durante a realização das atividades as puérperas raramente realizavam questionamentos, porém, a maioria dos questionamentos estava relacionada ao uso da cinta abdominal e à amamentação, sendo que para este último, a principal dúvida estava associada à presença de fissuras mamilares. Os acompanhantes, que em sua maioria eram maridos ou namorados, mantinham alguns questionamentos sobre a diástase do músculo reto abdominal e a amamentação.

Ao final da atividade, a maioria das puérperas demonstrava surpresa ao receber a cartilha educativa, e apresentavam maior surpresa quando informadas que poderiam levar o material para casa, para manutenção dos exercícios no domicílio.

\section{DISCUSSÃO}

Seguindo os pressupostos da Política Nacional de Atenção Integral à Saúde da Mulher, os encontros promovidos pelas acadêmicas desta pesquisa foram constituídos por atividades de educação em saúde no pós-parto imediato. Nesta fase, as orientações dos profissionais da saúde visaram a diminuir desconfortos e dificuldades da puérpera, sanar dúvidas e auxiliar no aumento da confiança da mulher em relação ao próprio corpo ${ }^{21}$.

Todas as puérperas deste estudo afirmaram satisfação com a intervenção fisioterapêutica, tipo educação em saúde. Além disso, a maioria das participantes respondeu que as condutas apresentadas foram melhores do que esperado e ideais para a resposta a questionamentos e dúvidas pessoais a respeito do pós-parto. As puérperas também relataram que a confiança demonstrada pelas acadêmicas de Fisioterapia superou as expectativas e afirmaram que participariam novamente de encontros semelhantes e indicariam as condutas para outras mulheres.

Com base nos relatos das puérperas e na satisfação com o atendimento fisioterapêutico, é válido incentivar a realização de atividades educativas em saúde no puerpério. Estas ações tornam-se ponte entre o campo científico e a comunidade e podem ser utilizadas como uma grande estratégia para a prevenção de intercorrências, promoção da saúde, além da minimização da insegurança que pode estar presente durante o período

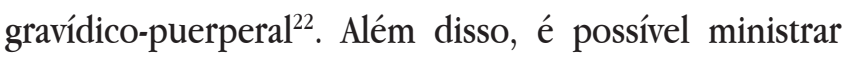
atividades e intervenções de maneira simples e didática, sem despender de recursos financeiros elevados ${ }^{23}$. Neste estudo, por exemplo, as discentes de Fisioterapia utilizaram recursos visuais, material didático impresso e instruções verbais como principais fontes de transmissão de informação para as puérperas, e os resultados obtidos no estudo mostraram-se satisfatórios.

Apesar de seus benefícios, as ações de promoção à saúde de puérperas são escassas, visto que a maioria das intervenções realizadas nesse período tem enfoque em orientações relacionadas ao cuidado do recém-nascido, e não ao esclarecimento de dúvidas ou aconselhamento da mulher em relação aos cuidados com ela mes$\mathrm{ma}^{22}$. Este fato pode causar descontentamento na fase do puerpério ${ }^{17,18,19}$, visto que as mulheres conferem grande importância a esse período ${ }^{18}$. Na pesquisa de Sword e Watt ${ }^{24}$, com 1.100 puérperas, $41 \%$ a $51 \%$ das mulheres gostariam de receber mais informações a respeito de alterações físicas pós-parto. Na presente pesquisa, as atividades propostas pelas acadêmicas mantiveram o enfoque nos principais desconfortos das puérperas. Além disso, a atenção das acadêmicas estava direcionada às mulheres durante os encontros e o principal objetivo era transmitir as informações de maneira clara e objetiva, de forma a esclarecer dúvidas e questionamentos pessoais. Estas abordagens podem ter favorecido a satisfação das puérperas em relação ao atendimento fisioterapêutico, visto que uma das solicitações prevalentes de pacientes atendidos e avaliados por profissionais da saúde em outros estudos é a dedicação de maior tempo ao esclarecimento de dúvidas e prestação de orientações ${ }^{19,25}$.

Apesar disso, algumas puérperas relataram raiva ou frustração com a Educação em Saúde recebida, porém não expuseram comentários, o que facilitaria na análise crítica referente a essa atividade. Uma análise cruzada destas respostas com as demais do questionário e com a satisfação de todas as puérperas com a educação em saúde oferecida pela fisioterapia, pode-se supor uma equivocada interpretação das perguntas, haja visto que o instrumento apresenta, além de escrita, figuras (emojis) representativas quanto à satisfação. Desta forma, perguntas que eram negativas podem haver sido erroneamente assinaladas como positivas, verificando apenas 
a "carinha feliz", ao invés de atender às instruções para preenchimento do questionário.

Cabe ressaltar que, atualmente, o profissional da saúde é instigado a atuar em diversos campos da prática clínica e precisa estar apto a elaborar ações de atenção à saúde voltadas a atender as reais necessidades da população. Desta forma, as atividades de extensão universitária permitem que os acadêmicos desenvolvam atividades resolutivas de situações e problemas de saúde reais, o que demonstra a contribuição social da academia para a comunidade, além de favorecer o aprimoramento da formação e capacitação profissional26,27. As atividades desta pesquisa favoreceram o fortalecimento de ações do ensino-serviço, visto que as acadêmicas expuseram a atuação do fisioterapeuta no puerpério imediato à equipe multiprofissional da instituição e as puérperas. Este é um ponto relevante deste estudo visto que a maternidade na qual foi realizada a presente pesquisa não ofertava $o$ atendimento fisioterapêutico (individual ou coletivo) às puérperas devido à ausência do profissional na instituição.

Neste estudo, a relação das acadêmicas de Fisioterapia com a equipe multiprofissional, as pacientes (puérperas) e a docente coordenadora do projeto, foram relevantes para a construção de reflexões acerca de situações reais da prática clínica fisioterapêutica em obstetrícia. Além disso, as atividades contribuíram para a elaboração de estratégias voltadas a atender às demandas das puérperas e funcionaram como forma de incentivo à atuação das futuras profissionais na área da Fisioterapia Obstétrica.

Com base nestes resultados, retifica-se a importância da presença dos fisioterapeutas em maternidades visto que a atuação deste profissional é relevante para melhoria da prestação de cuidados à puérpera ${ }^{15}$. Além disso, avaliar a satisfação da paciente quanto ao atendimento significa verificar qual a qualidade da assistência que está sendo prestada e se são necessárias modificações no plano de atendimento para facilitar a resolução de complicações e desconfortos ${ }^{9}$.

Vale ressaltar que faltam estudos acerca da educação em saúde realizada por fisioterapeutas no pós-parto imediato e que avaliem o grau de satisfação das puérperas perante o atendimento, além de pesquisas que enfatizem para outros temas relacionados no puerpério.

\section{CONCLUSÃO}

Estratégias fisioterapêuticas de educação em saúde no pós-parto imediato, conduzidas com utilização de materiais de apoio simples e de baixo custo, foram satisfatórias para mulheres do puerpério imediato, devendo ser incentivadas e implementadas como uma das rotinas nas maternidades brasileiras.

\section{REFERÊNCIAS}

1. Brasil. Ministério da Saúde. Secretaria de Gestão do Trabalho e da Educação na Saúde. Departamento de Gestão e da Regulação do Trabalho em Saúde. Câmara de Regulação do Trabalho em Saúde. Brasília, 2006.

2. Alves, VS. Um modelo de educação em saúde para o Programa Saúde da Família: pela integralidade da atenção e reorientação do modelo assistencial. Interface. 2005 ; 9 (16): 39-52.

3. Santos ACC, Ferreira EJ, Santos L dos, Souza OSQ. Relato de experiência no contexto da educação em saúde o cuidado maternoinfantil. J Nurs UFPE. 2015; 9: 8474-8.

4. Vieira F, Bachion MM, Salge AKM, Munari DB. Diagnósticos de enfermagem na Nanda no período pós-parto imediato e tardio. Esc Anna Nery. 2010; 14 (1): 83-9.

5. Silva LA, Nakano AMS, Gomes FA, Stefanello J. Significados atribuídos por puérperas adolescentes à maternidade: autocuidado e cuidado com o bebê. Texto \& contexto enferm. 2009 jan-mar; 18 (1): 48-56.

6. Cabral FB, Oliveira DLLC. Vulnerabilidade de puérperas na visão de Equipes de Saúde da Família: ênfase em aspectos geracionais e adolescência. Rev Esc Enferm USP. 2010; 44 (2): 368-75. 
7. Brasil. Ministério da Saúde, Secretaria de Atenção à Saúde, Departamento de Ações Programáticas Estratégicas, Área Técnica de Saúde da Mulher. Pré-natal e Puerpério: atenção qualificada e humanizada - manual técnico. Brasília, 2006.

8. Souza ABQ, Fernandes BM. Diretriz para assistência de enfermagem: ferramenta eficaz para a promoção da saúde no puerpério. Rev Rene. 2014; 15 (4): 594604 .

9. Andrade RD, Santos JS, Maia MAC, Mello DF. Fatores relacionados à saúde da mulher no puerpério e repercussões na saúde da criança. Esc Anna Nery 2015; 19 (1): 181-186.

10. Santos ACC, Ferreira EJ, Santos L dos, Souza OSQ. Relato de experiência no contexto da educação em saúde o cuidado maternoinfantil. J Nurs UFPE. 2015; 9: 8474-8.

11. Brasil. Ministério da Educação. Resolução CNE/CES 3/2014. Diário Oficial da União, Brasília, 23 de junho de 2014 - Seção 1 - p. 8-11. Brasília, 2014.

12. Panúncio-Pinto MP, Rodrigues MLV, Fiorati RC. Novos cenários de ensino: a comunidade e o território como espaços privilegiados de formação de profissionais da saúde. Medicina (Ribeirão Preto). 2015; 48 (3): 257-64.

13. Nankwanga A, Phillips J. Factors influencing utilisation of postnatal services in Kampala, Uganda. Journal of Community and Health Sciences. 2008; 3 (01): 19- 27.

14. Neuwald MF, Alvarenga LF. Fisioterapia e educação em saúde: investigando um serviço ambulatorial do SUS. Boletim Saúde. 2005; 19: 73-82.

15. Odunaiya NA, Ilesanmi T, Fawole AO, Oguntibeju OO. Attitude and practices of obstetricians and gynecologists towards involvement of physiotherapists in management of obstetric and gynecologic conditions. Int J Womens Health. 2013; 3 (5): 109-114.

16. Oliveira JB, Quirino GS, Rodrigues DP. Percepção das puérperas quanto aos cuidados prestados pela equipe de saúde no puerpério. Rev Rene. 2012; 13 (1): 74-84.

17.Dodou HD, Oliveira TDA, Oriá MOB, Rodrigues DP, Pinheiro PNC, Luna IT. Educational practices of nursing in the puerperium: social representations of puerperal mothers. Rev Bras Enferm. 2017; 70 (6): 1250-8.

18. Correa MSM, Feliciano KVO, Pedrosa EN, Souza AI. Acolhimento no cuidado à saúde da mulher no puerpério. Cad Saude Publica. 2017; 33 (3).

19. Correa MS, Feliciano KV, Pedrosa EN, Souza AI. Women's perception concerning health care in the post-partum period: a meta-synthesis. Open J Obstet Gynecol 2014; 4: 416-26.

20. Fornell, C. et al. The American customer satisfaction index: nature, purpose, and findings. Journal of Marketing. 1996; 60 (4): 07-18.

21. Guerreiro EM, Rodrigues DP, Azevedo AB, Ferreira, MA. Educação em saúde no ciclo gravídico-puerperal: sentidos atribuídos por puérperas. Rev. bras. enferm. 2014: 67 (1); 13-21.

22. Brasil. Ministério da Saúde. Secretaria de Atenção à Saúde. Departamento de Atenção Básica. Saúde da Criança: Nutrição Infantil, aleitamento materno e alimentação complementar. Caderno de Atenção Básica. Brasília, 2009.

23. Santos RV, Penna CMM. A educação em saúde como estratégia para o cuidado à gestante, puérpera e ao recém-nascido. Texto contexto - enferm. 2009; 18 (4): 652-660.

24. Sword W, Watt S. Learning needs of postpartum women: Does socioeconomic status matter? Birth. 2005: 32, 86-92.

25. Lopes GVDO, Menezes IMO, Miranda AC, Araujo KL, Guimarães ELP. Acolhimento: quando o usuário bate à porta. Rev Bras Enferm 2014; 67: 104-10. 
26. Baldoino AS, Veras RM. Análise das atividades de integração ensino-serviço desenvolvidas nos cursos de saúde da Universidade Federal da Bahia. Ver Esc Enferm USP. 2016; 50: 17-24.

27. Silva TS, Melo RO, Sodré MP, Moreira RCR, Souza ZCSN. A extensão universitária e a prevenção da violência obstétrica. Rev. Ciênc. Ext. 2017; 13 (1): 176189.

Recebido em: 21/10/2018

Aceito em: 28/12/2018 